\title{
SISTEM PENDUKUNG KEPUTUSAN SELEKSI PEMAIN MENGGUNAKAN METODE PROFILE MATCHING PADA BAHAR FUTSAL
}

\author{
Henri Setiawan $^{1}$, Dian Nur Sholihaningtias ${ }^{2}$, Fery Rahmawan Asma ${ }^{3}$ \\ ${ }^{1,2,3}$ Teknik Informatika. Universitas Indraprasta PGRI \\ Jl. Raya Tengah No.80, Kel Gedong, Kec. Pasar Rebo, Jakarta Timur \\ 1henrysetiawan216@gmail.com, 22dian.tyash@gmail.com, ${ }^{3}$ ferytijany489@gmail.com
}

\begin{abstract}
ABSTRAK
Futsal adalah olahraga sepak bola di dalam ruangan yang di dalam satu tim terdapat 5 pemain. Namun sering kali sulit untuk menentukan kemampuan pemain terbaik. Terlepas dari insting pelatih yang tajam, pelatih membutuhkan sebuah sistem yang dapat membantu menyediakan pilihan sebagai sarana pendukung dalam mengambil keputusan. Selama ini, penentuan pemain terbaik dilakukan secara manual dengan menggunakan file kertas penilaian pemain. Sehingga, penilaian pelatih kurang tepat dalam menentukan pemain karena hanya mengandalkan insting. Tujuan penelitian ini untuk mengatasi permasalahan tersebut, yaitu dengan merancang sebuah sistem menggunakan metode Profile Matching sebuah mekanisme pengambilan keputusan dengan mengasumsikan bahwa terdapat tingkat variable predicator yang ideal, untuk dimiliki pemain, pada metode ini kemampuan tiap individu dengan posisi pemain berdasarkan kriteria yang digunakan adalah stamina, kecepatan, kekuatan, kerja sama dan pengalaman. Pemilihan presentase di bagi menjadi dua aspek yaitu aspek teknik dan wawasan. Presentase penilaian di mulai dari pemilihan core factor dan secondary factor dengan bobot $60 \%$ dan $40 \%$. Di lanjutkan perhitungan nilai total dan perangkingan. Dengan metode profile matching sistem pendukung keputusan hasil seleksi pemain akan di masukkan dalam tim inti club, berdasarkan nilai rangking tertinggi dan dapat memudahkan pekerjaan pelatih dalam seleksi pemain.
\end{abstract}

Kata Kunci: Sistem Pendukung Keputusan, Pemain Futsal, metode Profile Matching, Java, Netbeans.

\begin{abstract}
Futsal is an indoor soccer sport where there are 5 players in one team. However, it is often difficult to determine the ideal player in a Team. Apart from sharp instinct coach, coaches need a system that can help provide choices as a means of support in making decisions. Player's ability is manually by using a paper of player assessment. Thus, the coach's assessment is less precise in determining the player's because it only relies on instinct. The purpose of this study is to overcome these problems, matching a decision-making mechanism by assuming that there is a level. Variable predictor the ideal for players to have, in this method the ability of each individual with the player's based on the criteria used are stamina, speed, strength, cooperation and experience. Selection of percentage is divided into two aspects: the techniques and insights. The percentage of assessment starts from the selection of the core factor and secondary factor with weights of $60 \%$ and $40 \%$. Continued calculation of the total value and ranking. profile matching the decision support system for player results will be included in the club's core team, based with highest ranking value and ease the coach's work in player selection.
\end{abstract}

Key Word: Decision Support System, Futsal Player,Method Profile Matching, Java, Netbeans.

\section{PENDAHULUAN}

Futsal adalah olahraga sepak bola di dalam ruangan yang di dalam satu tim terdapat 5 pemain. Ukuran lapangan futsal sendiri relative lebih kecil yaitu 26 x16 meter untuk standar nasional dan 40 × 20 meter untuk standar internasional Menurut Rina Darniyati (2018:61). Posisi pemain yang sesuai dengan karakter dan kriteria yang di harapkan, di butuhkan insting pelatih yang tajam dan sebuah sistem yang dapat membantu menyediakan pilihan sebagai sarana pendukung dalam mengambil keputusan. Dalam penentuan posisi pemain, pelatih melakukan secara hitung manual dengan mencatat pada kertas. Form penilaian kriteria pemain dan karakter setiap individu kurang tepat dalam menentukan penilaian posisi pemain yang ideal. Karena, pelatih hanya mengandalkan insting. Oleh karena itu, dengan penerapan metode Profile Matching ini akan memberikan manfaat dalam menguji kemampuan tiap individu dengan posisi pemain berdasarkan kriteria-kriteria yang telah di tentukan dengan tepat serta mengurangi adanya human error.

Tujuan Penelitian 
1. Untuk mengetahui pengembangan sistem pendukung keputusan yang sesuai dan layak diterapkan di seleksi pemain terbaik.

2. Untuk mengetahui seleksi pemain futsal dengan akurat, tepat dan sesuai

\section{Manfaat Hasil Penelitian}

1. Untuk menambah wawasan dan ilmu pengetahuan yang berkaitan dengan seleksi data pemain di sebuah pertandingan futsal.

2. Hasil penelitian sistem seleksi pemain futsal terbaik dapat diterapkan untuk mempermudah proses seleksi.

\section{METODE PENELITIAN}

Menurut John W. Craswell pada Ahmad Kosasih (2018:122) metode grounded research yaitu suatu metode penelitian berdasarkan pada fakta dan menggunakan analisis perbandingan dengan tujuan mengadakan generalisasi empiris, menetapkan konsep, membuktikan teori, mengembangkan teori, pengumpulan dan analisis data dalam waktu yang bersamaan. Karena metode penelitian yang digunakan untuk menghasilkan pemain tertentu dan menguji keefektifan pemain tersebut. Untuk menghasilkan pemain tertentu digunakan penelitian yang bersifat analisis kebutuhan dan untuk menguji keefektifan pemain tersebut supaya dapat bermain dengan posisi nya masing-masing pada klub Bahar Futsal Depok, maka diperlukan penelitian untuk menguji keefektifan pemain tersebut. Dalam penelitian ini metode pengumpulan data yang digunakan adalah Observasi, wawancara, dan metode kepustakaan. Dalam mengembangkan sistem dibutuhkan desain sistem untuk menentukan bagaimana suatu sistem akan menyelesaikan apa yang harus di selesaikan. Penulis disini mengembangkan sistem dengan menggunakan model waterfall.

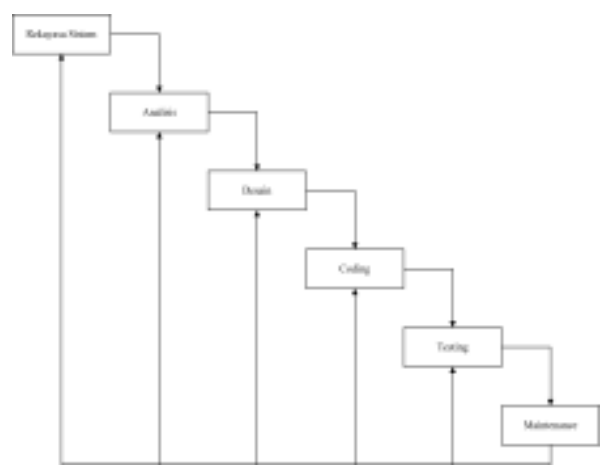

Gambar 1. Waterfall Model
Penelitian dilaksanakan di Bahar Futsal Depok, yang terletak di Jl. Raya Sawangan No.25, Mampang, Kec. Pancoran Mas, Kota Depok, Jawa Barat 16436.

\section{HASIL DAN PEMBAHASAN \\ Definisi Masalah}

Saat ini olahraga sudah bertumbuh sangat pesat, begitu pun di Indonesia. Di Indonesia kini sudah beragam favorit macam-macam olahraga, seperti futsal contohnya. Perkembangan futsal yang maju di Indonesia membuat banyak sekali turnamen-turnamen yang menyelenggarakan kompetisi futsal dari tingkat kampung hingga tingkat nasional. Dengan menentukan pemain yang bagus untuk dimainkan menggunakan insting, kadang juga pelatih hanya memilih pemain yang hanya pelatih percaya yang membuat dalam sebuah tim tidak efisien dan tidak fair.

\section{Penyelesaian Masalah}

Untuk menyelesaikan masalah ini, dibutuhkan media atau aplikasi sistem seleksi untuk menguji kemampuan setiap individu dengan posisi pemain berdasarkan kriteria kriteria yang telah di tentukan. Penggunaan metode yang dipakai penulis untuk membuat aplikasi seleksi pemain futsal ini adalah metode Profile Matching. Dengan menggunakan metode profile matching di harapkan pelatih dapat menyeleksi pemain futsal dengan kriteria kriteria yang telah di tentukan. Dengan metode profile matching di dapat hasil seleksi pemain yang akan di masukkan dalam tim inti club, berdasarkan nilai rangking tiap pemain.

\section{Algoritma Penyelesaian Masalah Dengan Flowchart dan Pseudocode}

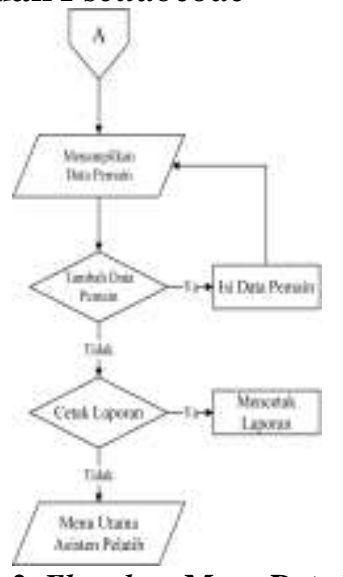

Gambar 2. Flowchart Menu Data Pemain 


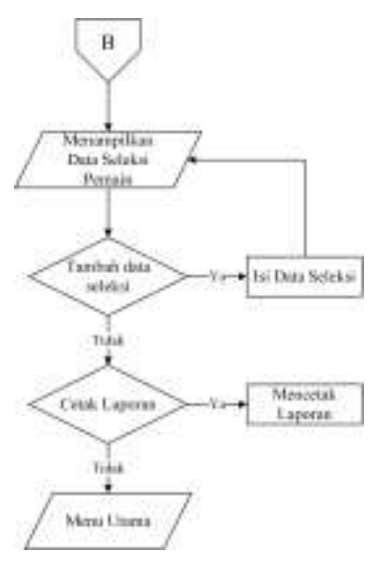

Gambar 3. Flowchart Menu Seleksi Pemain

\section{Pseudocode}

a. Menu Data Pemain

DataPemain.create()

Button_TambahDataPemain.create()

Button_EditDataPemain.create()

Button_HapusDataPemain.create()

Button_CetakLaporan.create()

Button_Kembali.create()

IF Button_TambahDataPemain.click() THEN

TambahDataPemain.start()

IF Button_EditDataPemain.click() THEN

EditDataPemain.start()

IF Button_HapusDataPemain.click() THEN

HapusDataPemain.start()

ELSE IF Button_CetakLaporan.click() THEN Laporan.start()

ELSE IF Button_Kembali.click() THEN

MenuUtamaPelatih.start()

END IF

b. Menu Seleksi Pemain

SeleksiPemain.create()

Button_TambahDataSeleksi.create()

Button_EditDataSeleksi.create()

Button_HapusDataSeleksi.create()

Button_CetakLaporan.create()

Button_Kembali.create()

IF Button_TambahDataSeleksi.click() THEN

TambahDataSeleksi.start()

IF Button_EditDataSeleksi.click() THEN

EditDataSeleksi.start()

IF Button_HapusDataSeleksi.click() THEN

HapusDataSeleksi.start()

ELSE IF Button_CetakLaporan.click()
THEN Laporan.start()

ELSE IF Button_Kembali.click()

THEN

MenuUtamaPelatih.start() END IF

\section{Uji Coba Program dengan Contoh Data}

Berikut ini adalah Uji coba program dengan contoh data yang dibuat dengan bahasa pemrograman Java dan IDE Netbeans dan database menggunakan MySQL:

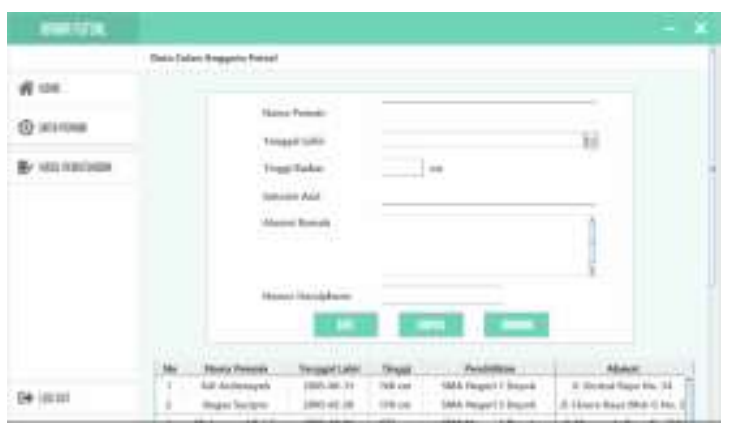

Gambar 4. Menu Data Pemain

Pada menu Data Pemain hanya ada di akun berposisi asisten pelatih. Data pemain digunakan untuk mengetahui data diri pemain yang ada pada tim futsal. Tabel data pemain berisi informasi nama pemain, tanggal lahir, tinggi, Pendidikan, alamat, nomor handphone dan status seleksi. Selain itu user juga dapat menambah data pemain, menghapus salah satu data pemain dan mengubah isi data pemain jika diinginkan.

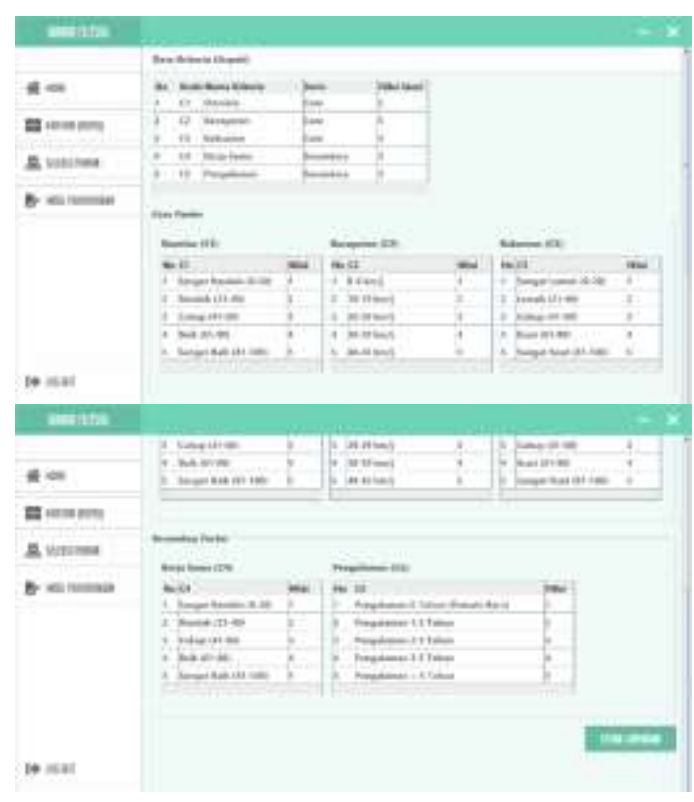

Gambar 5. Menu Kriteria (Aspek) 
Pada menu Kriteria (Aspek) hanya ada di akun berposisi pelatih. User dapat mengetahui informasi tabel data kriteria beserta nilainya dan atribut range nilai. Data kriteria digunakan untuk mengelompokkan nilai dari setiap atribut yang nilainya akan dijadikan acuan dalam sistem pendukung keputusan. Tabel data kriteria berisi informasi kode kriteria, nama kriteria dan nilai.

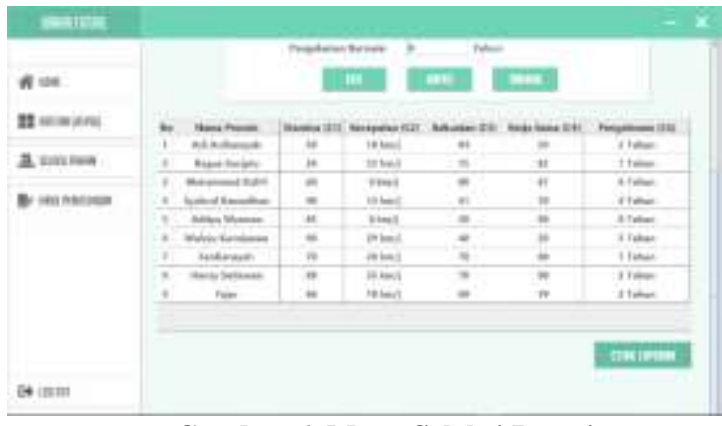

Gambar 6. Menu Seleksi Pemain

Pada menu Seleksi Pemain hanya ada di akun berposisi pelatih. User dapat mengetahui informasi pada tabel seleksi pemain. Seleksi pemain digunakan untuk mengetahui data nilai pemain yang ada pada tim futsal. Tabel seleksi pemain berisi informasi nama pemain, nilai stamina, nilai kecepatan, nilai kekuatan, nilai kerja sama, dan pengalaman. Selain itu user juga dapat menambah data seleksi pemain, menghapus salah satu data seleksi pemain dan mengubah isi data seleksi pemain jika diinginkan.

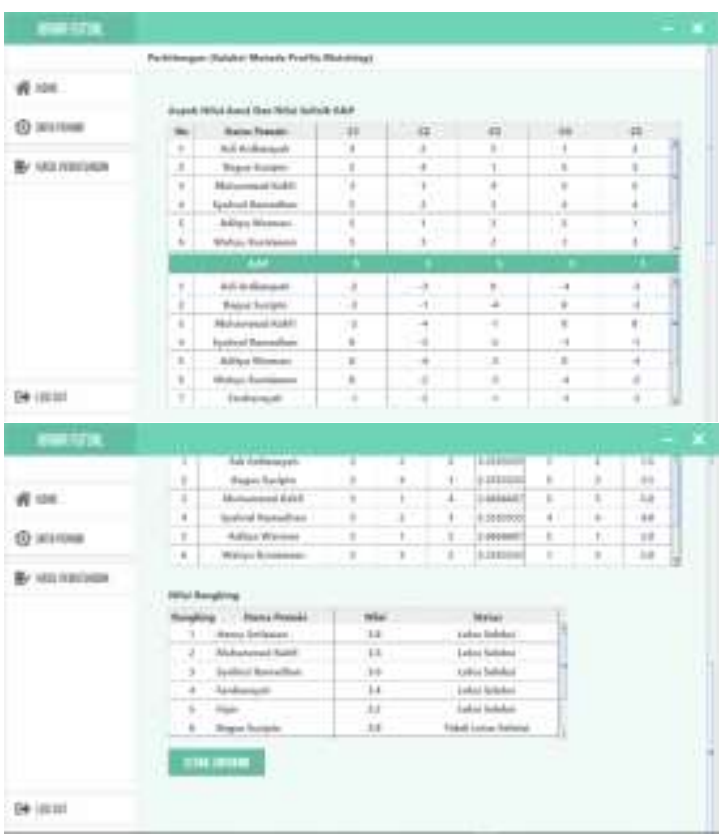

Gambar 7. Menu Hasil Perhitungan Asisten Pelatih

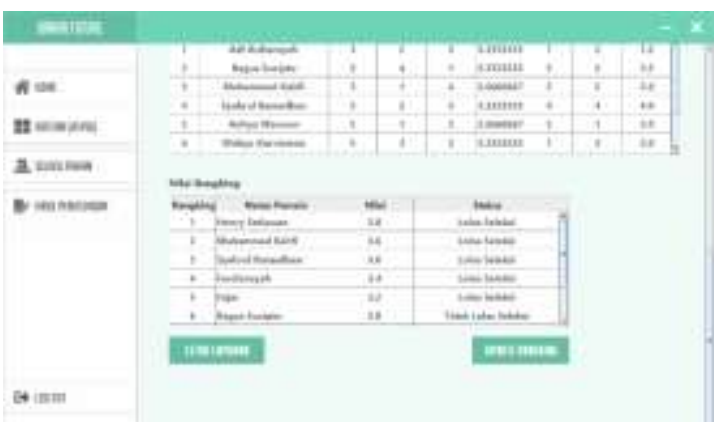

Gambar 8. Menu Hasil Perhitungan Pelatih

Pada menu Hasil Perhitungan ada di kedua akun berposisi pelatih dan asisten pelatih. Menu ini merupakan hasil nilai dari data seleksi pemain yang sudah di input user sebelumnya. Nilai-nilai tersebut diproses dengan perhitungan sistem pendukung keputusan metode Profile Matching menjadi tabel NCF \& NSF. Setelah itu nilai akan di proses sehingga menjadi nilai rangking.

\section{Pembahasan Hasil Uji Coba}

\section{a. Pada gambar 6 Menu Seleksi Pemain}

Tabel 1. Data Kriteria (Aspek)

\begin{tabular}{|c|l|c|c|}
\hline Kode & Nama Kriteria & Jenis & $\begin{array}{c}\text { Nilai } \\
\text { Ideal }\end{array}$ \\
\hline C1 & Stamina & Core & 5 \\
\hline C2 & Kecepatan & Core & 5 \\
\hline C3 & Kekuatan & Core & 5 \\
\hline C4 & Kerja Sama & Secondary & 5 \\
\hline C5 & Pengalaman & Secondary & 5 \\
\hline
\end{tabular}

\section{b. Pada gambar 7 Menu Hasil Perhitungan Asisten Pelatih}

\section{Perhitungan Nilai GAP dan Pembobotan}

Tabel 2. Perhitungan Selisih Nilai Gap

\begin{tabular}{|c|c|c|c|c|c|c|}
\hline No & Nama Pemain & C1 & C2 & C3 & C4 & C5 \\
\hline 1 & Adi Ardiyansyah & 3 & 2 & 5 & 1 & 2 \\
\hline 2 & Bagus Sucipto & 2 & 4 & 1 & 5 & 2 \\
\hline 3 & Muhammad Kahfi & 3 & 1 & 4 & 5 & 5 \\
\hline \multicolumn{2}{|r|}{ GAP } & 5 & 5 & 5 & 5 & 5 \\
\hline 1 & Adi Ardiansyah & -2 & -3 & 0 & -4 & -3 \\
\hline 2 & Bagus Sucipto & -3 & -1 & -4 & 0 & -3 \\
\hline 3 & Muhammad Kahfi & -2 & -4 & -1 & 0 & 0 \\
\hline
\end{tabular}


Tabel 3. Pembobotan

\begin{tabular}{|c|c|c|c|}
\hline No & $\begin{array}{c}\text { Selisih } \\
\boldsymbol{G A P}\end{array}$ & $\begin{array}{c}\text { Bobot } \\
\text { Nilai }\end{array}$ & Keterangan \\
\hline 1 & 0 & 5 & $\begin{array}{c}\text { Tidak ada selisih } \\
\text { (kompetensi sesuai dengan } \\
\text { yang dibutuhkan }\end{array}$ \\
\hline 2 & 1 & 4,5 & $\begin{array}{c}\text { Kompetensi individu } \\
\text { kelebihan 1 tingkat/level }\end{array}$ \\
\hline 3 & -1 & 4 & $\begin{array}{c}\text { Kompetensi individu } \\
\text { kekurangan 1 tingkat/level }\end{array}$ \\
\hline 4 & 2 & 3,5 & $\begin{array}{c}\text { Kompetensi individu } \\
\text { kelebihan 2 tingkat/level }\end{array}$ \\
\hline 5 & -2 & 3 & $\begin{array}{c}\text { Kompetensi individu } \\
\text { kekurangan 2 tingkat/level }\end{array}$ \\
\hline 6 & 3 & 2,5 & $\begin{array}{c}\text { Kompetensi individu } \\
\text { kelebihan 3 tingkat/level }\end{array}$ \\
\hline 7 & -3 & 2 & $\begin{array}{c}\text { Kompetensi individu } \\
\text { kekurangan 3 tingkat/level }\end{array}$ \\
\hline 8 & 4 & 1,5 & $\begin{array}{c}\text { Kompetensi individu } \\
\text { kelebihan 4 tingkat/level }\end{array}$ \\
\hline 9 & -4 & $\begin{array}{c}\text { Kompetensi individu } \\
\text { kekurangan 4 tingkat/level }\end{array}$ \\
\hline
\end{tabular}

Tabel 4. Bobot Nilai

\begin{tabular}{|c|l|c|c|c|c|c|}
\hline No & Nama Pemain & B1 & B2 & B3 & B4 & B5 \\
\hline 1 & Adi Ardiyansyah & 3 & 2 & 5 & 1 & 2 \\
\hline 2 & Bagus Sucipto & 2 & 4 & 1 & 5 & 2 \\
\hline 3 & Muhammad Kahfi & 3 & 1 & 4 & 5 & 5 \\
\hline
\end{tabular}

Perhitungan dan Pengelompokan Core Factor dan Secondary Factor

Setelah bobot nilai ditentukan maka dibagi menjadi 2 kelompok yaitu core factor dan secondary factor.

1) Rumus untuk menghitung core factor adalah sebagai berikut:

$$
N C F=\frac{\Sigma N C(\text { aspek })}{\Sigma I C}
$$

Sedangkan rumus untuk mengitung secondary factor adalah sebagai berikut:

$$
N S F \frac{\Sigma N S(\text { aspek })}{\Sigma I S}
$$

Jika core factor adalah Stamina (C1), Kecepatan (C2) dan Kekuatan (C3) sedangkan yang menjadi secondary factor adalah Kerja Sama (C4) dan Pengalaman (C5). Maka perhitungan core factor dan secondary factor adalah sebagai berikut:

1) Adi Ardiansyah

$$
\begin{aligned}
\mathrm{NCF} & =(\mathrm{B} 1+\mathrm{B} 2+\mathrm{B} 3) / 3 \\
& =(3+2+5) / 3 \\
& =3,3333333 \\
\mathrm{NSF} & =(\mathrm{B} 4+\mathrm{B} 5) / 2
\end{aligned}
$$

$$
=(1+2) / 2
$$$$
=1,5
$$

2) Bagus Sucipto

$$
\begin{aligned}
\mathrm{NCF} & =(\mathrm{B} 1+\mathrm{B} 2+\mathrm{B} 3) / 3 \\
& =(2+4+1) / 3 \\
& =2,3333333 \\
\mathrm{NSF} & =(\mathrm{B} 4+\mathrm{B} 5) / 2 \\
& =(5+2) / 2 \\
& =3,5
\end{aligned}
$$

3) Muhammad Kahfi

$$
\begin{aligned}
\mathrm{NCF} & =(\mathrm{B} 1+\mathrm{B} 2+\mathrm{B} 3) / 3 \\
& =(3+1+4) / 3 \\
& =2,6666667 \\
\mathrm{NSF} & =(\mathrm{B} 4+\mathrm{B} 5) / 2 \\
& =(5+5) / 2 \\
& =5
\end{aligned}
$$

c. Pada gambar 8 Menu Hasil Perhitungan Pelatih

\section{Perhitungan Nilai Total}

Untuk menghitung nilai total, rumus yang digunakan yaitu:

\section{(x)\% NCF(aspek) + (x)\% NSF(aspek) $=\mathbf{N t o t a l}($ aspek $)$}

Bila input persentase core factor adalah $60 \%$ dan secondary factor adalah $40 \%$, maka perhitungan nilai total adalah sebagai berikut:

1) Adi Ardiansyah

$$
\begin{aligned}
\mathrm{N} & =(60 \% * \mathrm{NCF})+(40 \% * \mathrm{NSF}) \\
& =(60 \% * 3,3333333)+(40 \% * 1,5) \\
& =2,6
\end{aligned}
$$

2) Bagus Sucipto

$$
\begin{aligned}
\mathrm{N} & =(60 \% * \mathrm{NCF})+(40 \% * \mathrm{NSF}) \\
& =(60 \% * 2,3333333)+(40 \% * 3,5) \\
& =2,8
\end{aligned}
$$

3) Muhammad Kahfi

$$
\begin{aligned}
\mathrm{N} & =(60 \% * \mathrm{NCF})+(40 \% * \mathrm{NSF}) \\
& =(60 \% * 2,66666667)+(40 \% * 5,0) \\
& =3,6
\end{aligned}
$$




\section{Pemberian Rangking}

Dengan Demikian, pemberian rangking mulai dari nilai total yang terbesar hingga yang terkecil.

Tabel 5. Hasil Ranking Pemain

\begin{tabular}{|c|c|c|c|}
\hline Rangking & Nama Pemain & Nilai & Status \\
\hline 1 & $\begin{array}{c}\text { Muhammad } \\
\text { Kahfi }\end{array}$ & 3,6 & Lolos Seleksi \\
\hline 2 & Bagus Sucipto & 2,8 & $\begin{array}{c}\text { Tidak Lolos } \\
\text { Seleksi }\end{array}$ \\
\hline 3 & Adi Ardiansyah & 2,6 & $\begin{array}{c}\text { Tidak Lolos } \\
\text { Seleksi }\end{array}$ \\
\hline
\end{tabular}

\section{SIMPULAN DAN SARAN}

Berdasarkan hasil pembahasan dari rumusan perancangan aplikasi sistem pendukung keputusan pemain futsal terbaik dengan metode Profile Matching, beberapa hal yang dapat disimpulkan adalah sebagai berikut: Metode Profile terdapat tingkat variabel prediktor yang ideal yang harus dipenuhi oleh subyek yang diteliti, bukannya tingkat minimal yang harus dipenuhi atau dilewati.Dapat disimpulkan bahwa akurasi sistem menggunakan metode Profile Matching berdasarkan dari 30 data uji yang berbeda metode menghasilkan tingkat akurasi yang baik dengan hasil decision maker sebesar $86,6 \%$.

Berdasarkan penelitian dan analisis yang diusulkan oleh penulis, maka demi tercapainya tujuan yang diharapkan, maka penulis dapat memberi saran sebagai berikut: Jadikan aplikasi ini sebagai alat bantu dalam mengambil keputusan memilih pemain futsal terbaik karena sebuah peforma pelatihan pemain futsal bisa berubah-ubah sesuai dengan kebugaran pemain. Melakukan analisis lebih lanjut dengan menguji kemampuan bertanding terhadap pemain futsal agar penilaian lebih akurat lagi kedepannya. Sebaiknya diaplikasikan dengan metode lain untuk membandingkan hasilnya.

\section{UCAPAN TERIMAKASIH}

Dalam penelitian ini saya ucapkan terima kasih kepada Bahar futsal Depok karena telah mengizinkan penilitian dan juga info sumber yang terkait membantu saya menyelesaikan penelitian ini.

\section{DAFTAR PUSTAKA}

Adhar, D. (2014). Sistem Pendukung Keputusan Pengangkatan Jabatan
Karyawan pada PT . Ayn dengan Metode Profile Matching. Jurnal Teknik Informatika Dan Sistem Informasi, 1(1), 1629.

http://jurnal.mdp.ac.id/index.php/jatisi/articl e/view/18

Aeni Hidayah, N., \& Fetrina, E. (2017). Rancang Bangun Sistem Pendukung Keputusan Kenaikan Jabatan Pegawai Dengan Metode Profile Matching (Studi Kasus: Kementerian Agama Kantor Wilayah DKI Jakarta). Studia Informatika: Jurnal Sistem Informasi, 10(2), 127-134.

Ambar T Sulistiyani. (2013). Pengertian seleksi. Journal of Chemical Information and Modeling, 53(9), 1689-1699.

Angeline, M., \& Astuti, F. (2018). Sistem Pendukung Keputusan Pemilihan Karyawan Terbaik Menggunakan Metode Profile Matching. Jurnal Ilmiah SMART, II(2), 45-51.

Bagaskara, D. F., Aruan, M. C., \& Saputra, S. (2018). Aplikasi Sistem Informasi Penyewaan Sportcenter Di Milano Futsal Cileungsi Menggunakan Java Deskstop. In Semnas Ristek (Seminar Nasional Riset Dan Inovasi Teknologi), 5(1), 1327-1331.

Damara, M. D., \& Anwar, S. N. (2020). Sistem Pendukung Keputusan Dengan Metode Profil Matching Untuk Seleksi Pemain Futsal ( Studi Kasus Di Asosiasi Futsal Kota U-19 Jepara ). 978-979.

Darniyati, R., Artha, E. U., \& Setiawan, A. (2018). Sistem Pendukung Keputusan Seleksi Pemain Pada Cabang Olahraga Futsal Dengan Metode Profile Matching. Jurnal Komtika - Komputasi Dan Informatika, 2(1), 61-70. https://doi.org/10.31603/komtika.v2i1.2 115

Djufri, I., \& Thais. A, I. (2020). Penentuan Pemain Utama Central Midfielder AIKOM Football Club Menggunakan Metode Profile Matching Dalam Sistem Pengambilan Keputusan. Journal of Science and Technolgy, 1, 130-141.

Hasugian, A. H., \& Cipta, H. (2018). Pengertian Sistem Pendukung Keputusan. Jurnal Ilmu Komputer Dan Informatika, 02(April).

Kosasih, A. (2018). Pendekatan Grounded Teori (Grounded Theory aprroach): Sebuah kajian sejarah, teori, prinsip dan strategi metodenya. Prosiding Seminar Hasil Penelitian Dosen UNINDRA, 5, 122-132. 